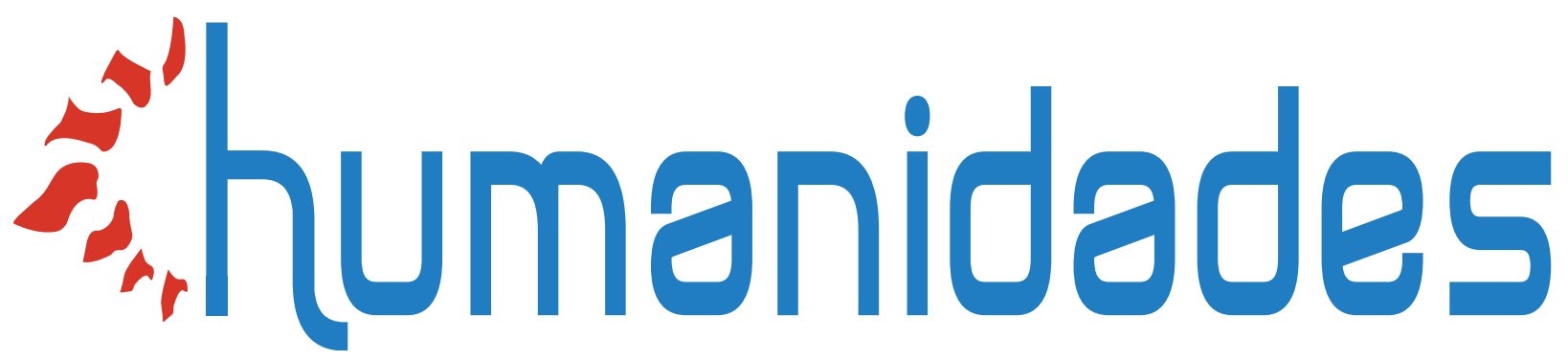

\title{
La fenomenología del amor de Ortega
}

\author{
Leopoldo Tillería Aqueveque
}

DOI: https://doi.org/ I0.155 I7/h.v10i2.4I6/2 https://revistas.ucr.ac.cr/index.php/humanidades/index 


\section{"humanidades}

Revista Humanidades

ISSN: 2215-3934

humanidades@ucr.ac.cr

Universidad de Costa Rica

Costa Rica

\section{La fenomenología del amor de Ortega}

Tillería Aqueveque, Dr. Leopoldo

La fenomenología del amor de Ortega

Revista Humanidades, vol. 10, núm. 2, 2020

Universidad de Costa Rica, Costa Rica

Disponible en: http://www.redalyc.org/articulo.oa?id=498062469009

DOI: https://doi.org/10.15517/h.v10i2.41612

Esta obra está bajo una Licencia Creative Commons Atribución-NoComercial-SinDerivar 3.0 Internacional. 
Desde las ciencias sociales, la filosofía y la educación

\title{
La fenomenología del amor de Ortega
}

\author{
The Ortega's Phenomenology of Love \\ Dr. Leopoldo Tillería Aqueveque \\ Instituto Profesional INACAP, Chile \\ leopoldo.tilleria@inacapmail.cl \\ iD http://orcid.org/0000-0001-5630-7552
}

DOI: https://doi.org/10.15517/h.v10i2.41612

Redalyc: http://www.redalyc.org/articulo.oa?

id $=498062469009$

Recepción: 21 Marzo 2020

Aprobación: 23 Abril 2020

\section{Resumen:}

El artículo aborda la fenomenología del amor en la filosofía de Ortega, especialmente a partir de su obra del periodo maduro Estudios sobre el amor (1939). Para ello, el escrito se organiza en torno a cinco conceptos que según Ortega describirían una nota esencial a su idea de amor: enamoramiento, entrega, elección, amor cortés y perfección. Esta recepción de la fenomenología del amor de Ortega adquiere una mayor claridad a partir de la consideración del amor como modo de afectividad propuesta, a su vez, por la fenomenología de Martin Heidegger. El amor orteguiano, expresión estética de su filosofía de la razón vital, muestra la preocupación del pensador español por explicar el acontecimiento amoroso a partir de la síntesis entre razón y vida, precisamente en el núcleo de nuestra circunstancia. Esta fenomenología del amor revelaría, a la postre, al héroe romántico como el único modo de ser que pudiera contrarrestar el nihilismo al que el español hizo frente mediante su filosofía de la vida.

Palabras clave: Amor, Elección, Filosofía.

\section{ABstRACT:}

The article discusses the phenomenology of love in the philosophy of Ortega, especially from his work of the mature period, Studies on Love (1939). Therefore, the writing is organized around five concepts that Ortega would describe an essential note to his idea of love: infatuation, delivery, choice, courtly love, and perfection. This reception of Ortega's phenomenology of love acquires greater clarity from the consideration of love as a mode of affectivity proposed, in turn, by Martin Heidegger's phenomenology. Ortega's Love, an aesthetic expression of his philosophy of vital reason, shows the Spanish thinker's concern to explain the love event from the synthesis between reason and life, precisely at the core of our circumstance. This species of phenomenology of love would reveal, to the end, the romantic hero as the only way of being that it could counteract the nihilism that the Spanish faced through his philosophy of life.

KeYwORDS: Love, Choice, Philosophy.

\section{INTRODUCCIÓN}

La filosofía de Ortega puede reconocerse, ante todo, como una filosofía de la vida y, al mismo tiempo, como una filosofía de la España vital (Ruiz, 2009, p. 72). Puede verse también como una filosofía literaria, la cual es herencia del modo de pensar de los escritores del 98. Ruiz, en cambio, la inscribirá en la corriente posmoderna integradora de filosofía y vida. Teniendo en cuenta esta influencia (a la que debemos agregar, entre otras, las de Kant, Nietzsche, Cohen, Scheler, Dilthey, Husserl y Bergson), quisiera hacer un breve comentario sobre la idea de amor en la filosofía orteguiana, seguramente una de sus regiones menos abordadas por la literatura contemporánea.

Partiré con una idea maciza del madrileño: "Es la filosofía la ciencia general del amor; dentro del globo intelectual representa el mayor ímpetu hacia una omnímoda conexión” (Ortega, 1966, p. 316). Obviamente, esta referencia platónica del amor hace alusión al carácter sintético que para Ortega debe definir al quehacer filosófico como búsqueda del sentido de las cosas. Dicho de otro modo: la meditación como ejercicio erótico (Ruiz, 2009, p. 242). Aun así, me parece un buen indicio, pero de esto no va la idea fundamental de amor en Ortega. Sus ideas principales sobre el amor (aquello que se podría llamar su auténtica preocupación por 
una filosofía del erotismo) pertenecen a su periodo de madurez filosófica, al llamado raciovitalismo, y están contenidas en gran parte en sus Estudios sobre el amor de 1939. Aquí es donde el filósofo se decidirá a realizar una fenomenología del amor propiamente tal. La obra la componen los opúsculos Facciones del amor, Amor en Stendhal, La elección en amor y Otros ensayos afines, entre los que destacan el epílogo al libro De Francesca a Beatrice, Para una psicología del hombre interesante, Para la historia del amor y Nota sobre el "amor cortés", varios de ellos publicados, como era costumbre en Ortega, en la Revista de Occidente de Madrid. La impronta fenomenológica de este trabajo de Ortega es observada por Carchidi:

En estos ensayos, el filósofo expone las determinaciones positivas y negativas del amor, a través de una serie de descripciones fenomenológicas influenciadas por la lectura de Pfänder y Scheler, los únicos que, en su opinión, habían buscado analizar la esencia del amor, distinguiéndolo del deseo (2002, p. 73).

Desde luego, designar a la filosofía de Ortega como fenomenología implica hacerse cargo de una argumentación que, cuando menos, debiera indicar su modo de filiación con algún tronco fenomenológico fundamental (por ejemplo, Schleiermacher, Husserl o Heidegger). Ahora bien, tal linaje fenomenológico que abordaré con más detalle en la sección que sigue- se halla completamente en el corazón del proyecto orteguiano, si entendemos que en la filosofía de la razón vital el ser es precisamente una interpretación de la vida humana, y que esta -en cuanto vida- no viene a ser nada más que la realidad indigente (Holzapfel, 2004). Tal como dice Haro, el amor que preocupa a Ortega en su etapa de las Meditaciones es el amor como ímpetu universal, bastante más cercano a la idea de amor y odio que tenían los griegos: "amor es conexión, dice Ortega inspirado, como veremos, por el pensamiento clásico griego (Sócrates y Platón), frente al odio que es inconexión y aniquilamiento -como afirma también Spinoza en la Parte Tercera de su Ética" (Haro, 2018, p. 178). Frente a esta indigencia, el amor será "el acto más delicado y total de un alma" (Ortega, 1981, p. 68), a tal punto que por medio de él convertimos a quien amamos en nuestro propio proyecto. Reinterpretando a Ortega, se diría que el amor es el absoluto acontecimiento.

En lo específico, me propongo en este escrito discutir lo que un poco abusivamente llamaré la teoría del amor de Ortega, intentando dilucidar -y diferenciar- qué es lo que esencialmente el filósofo hispano quiere decir en las ideas de enamoramiento, entrega, elección, amor cortés y perfección; modos que revelan una efectiva disposición fenomenológica del amor. En las bellas palabras de Haro: "como afán integral de comprensión de las cosas más nimias y en circunstancia para conducirlas a su máximo esplendor, plenitud de significado o perfección" (2018, p. 202). Junto con reconocer en la filosofía del amor de Ortega una genuina fenomenología, el diálogo con la comprensión fenomenológica heideggeriana del amor resultará, aquí, un asunto no solo natural, sino recurrente, signo -seguramente- de que sería mejor hablar de una única y misma fenomenología de cuño germánico y mediterráneo.

\section{LA RECEPCión FENOMENOLÓgica de ORTEga}

Ortega realiza una crítica a la fenomenología de Husserl, pero no en cuanto a su consideración como "filosofía de la vida", sino en relación con las insuficiencias que el filósofo ibérico advertía en la reducción fenomenológica del alemán. Lo que hace Ortega, entonces, no es renunciar al proyecto fenomenológico, sino transformar su método:

Cuando Ortega leyó a Husserl comprendió enseguida que la fórmula que en última instancia condensa su pensamiento filosófico (Yo soy yo y mi circunstancia y si no la salvo a ella no me salvo yo, O.C. I, 322) expresa la ejecutividad de esa acción irreductible que es la vida humana, justamente lo opuesto a la reducción fenomenológica que consiste en quedarse con la esencia de los datos sensibles "poniendo entre paréntesis" (Einklammerung) la realidad empírica del mundo y suspendiendo momentáneamente el acto consciente de vivir (López, 2000, p. 94).

Tuttle, en cambio, verá en la idea de Ortega que la vida no es ni una res Yo-independiente derivada de una posición realista, ni una pura conciencia carente de objetividad, una crítica directa al idealismo de Dilthey: 
Esta formulación de Ortega sugerirá a la vez la afirmación de Heidegger de que “estar en el mundo" es un componente existencial real del Dasein, idea, dicho sea de paso, para la cual Ortega reivindicó prioridad ideológica. Podemos notar, finalmente, que el mismo tono anti-idealista está presente en el análisis de Ortega del movimiento fenomenológico temprano en Alemania (Tuttle, 1981, p. 91).

$\mathrm{Al}$ respecto, tendré en vista una idea que San Martín (2012) expone en su libro La fenomenología de Ortega y Gasset, que señala -en lo esencial- que la fenomenología de Ortega es aquella filosofía llamada a recuperar la vida en toda su multiplicidad. En otras palabras: el mundo humano. De entrada, se puede decir que hay una especie de cerrojo que mantendrá impregnada la filosofía orteguiana de esa preocupación fundamental por la relación -en el mundo mismo- entre meditación y vida. Sería también oportuno decir que, si seguimos algo así como el índice de las obras de Ortega, el concepto de fenomenología no aparece precisamente en la primera línea de la especificación onomástica. Seguiré, pues, un argumento que indica -sobre todo considerando la crítica de San Martin- que Ortega habría desarrollado una fenomenología, no quiero decir encubierta, pero en buen grado no explícita en cuanto a su determinación programática. Tal perspectiva fenomenológica ha quedado sembrada en buena parte de sus textos fundamentales (¿Quées filosofía? y Meditaciones del Quijote) y posiblemente, también en sus ensayos sobre el amor.

Ahora, hay algo fundamental: la vinculación de los desarrollos de Ortega con los de Heidegger, que parecen correr parejos, aunque por carriles distintos. No seré yo quien descubra las coincidencias entre las filosofías de uno y otro pensador (una de cuyas claves, ¡cómo no!, es la conocida germanofilia de Ortega). Sin embargo, justamente porque de lo que se trata en este trabajo es de reconocer en Ortega una efectiva fenomenología del amor, quisiera fijarme en la propia fenomenología con que Heidegger, a su vez, determina al amor en cuanto afecto, particularmente en el periodo de Ser y tiempo y que será comentada por Klocker en su estudio de 2016.

Es indudable que la influencia de Husserl (como "padre fenomenológico") resulta decisiva en el método adoptado tanto por Heidegger como por Ortega (digamos, por sus filosofías tempranas). Sin ir más lejos, el concepto de ejecutividad de Ortega traduce directamente el vollziehen husserliano. Como base de mi conjetura, recurriré a una definición de fenomenología que, precisamente para incorporar lo que podría llamarse el factor historicidad, corresponde a la entregada por Martin Heidegger en su obra de 1927:

Fenomenología es el modo de acceso y de determinación evidenciante de lo que debe constituir el tema de la ontología. La ontología sólo es posible como fenomenología. El concepto fenomenológico de fenómeno entiende como aquello que se muestra el ser del ente, su sentido, sus modificaciones y derivados. Y este mostrarse no es un mostrarse cualquiera, ni tampoco algo así como un manifestarse [Erscheinen]. El ser del ente es lo que menos puede ser concebido como algo "detrás" de lo cual aún habría otra cosa que "no aparece" (Heidegger, 2002, p. 58).

Es la misma recepción que vemos en León: "La fenomenología es investigación sobre el ser de los entes. El ser de los entes es comprensible como 'fenómeno', es decir, en cuanto un mostrarse en su cómo” (2009, p. 4). No habría que olvidar, empero, que la diferencia primordial entre las fenomenologías de Husserl y Ortega radica no en la efectividad de la epojé, como actitud de suspensión de la transitividad de la relación concienciamundo, sino más bien en la condición absoluta o no de la reducción fenomenológica. La separación definitiva entre ambas fenomenologías supone lisa y llanamente que para Ortega no hay posibilidad de una reducción absoluta. Si la hubiere, ¿qué habría más allá del pensar? Gutiérrez lo aclara en mayor medida:

Ortega, lejos de considerar la reflexión como sustancia, como origen absoluto fundado sobre sí mismo y totalmente independiente de la conciencia natural, asegura que parte de una conciencia ejecutiva -la vida- que la rebasa, y en referencia a la cual se constituye la reflexión, volviendo para aclararla (1998, p. 120).

Pues bien, en este escrito se aborda el ser del amor. Para empezar, lo haré por una idea que en palabras del filósofo representa no precisamente su visión del amor, sino, para ser exactos, la de falso amor. En este caso, la idea de enamoramiento. 


\section{AMOR COMO ENAMORAMIENTO}

En sus escritos, Ortega define el enamoramiento (o sea, el falso amor o pseudoamor) como una especie de estado de misticismo, en el que nuestra vida queda literalmente prendida de los movimientos del otro, lo que significa que cuando nuestro filósofo habla del amor, no se refiere exactamente al cariño, al amour-vanité, al fervor sensual o al amor-pasión (todos pseudoamores). Digamos, simplemente, que se trata de lo que por lo común llamamos flechazo. Esto no significa en absoluto que el enamorado no sienta en algún momento de su plenitud, ilusión, cariño, deseo sexual o ensoñación. Lo importante es no confundirlos. Como sostiene Carchidi "El deseo, sin embargo, que puede extinguirse es el deseo como posesión, fenomenológicamente más parecido al instinto sexual, como afirmó Ortega” (2002, p. 78); en ningún caso la noción profunda o esencial del amor. Probablemente, este desapego de lo pasional podría explicarse por el presunto estoicismo que Ruiz ve en Ortega, el que se expresaría en "su obsesión por mantener a raya las pasiones, cuyo desbordamiento veía como uno de los vicios españoles que nos incapacitaba para la filosofía” (Ruiz, 2011, p. 349).

Ortega llama enamoramiento a una serie de procesos mentales, que funcionarían como inevitable "primera etapa" del amor verdadero. Es decir, a esos instantes en que reducimos nuestro habitual mundo para concentrarnos exclusivamente en quien amamos. Algunas veces denomina a este primer momento, encantamiento, otras, "imbecilidad transitoria", "parálisis de la atención", "estado de gracia" o "manía" (Ortega, 1981, p. 23). No es de extrañar, entonces, que el filósofo pragmatista termine haciendo una analogía entre este virtual aturdimiento del enamorado y, como decíamos, el éxtasis del místico o el trance del hipnotizado, especialmente considerando esa suerte de rapto o arrebato que parece signo común a estos tres estados: "El afán de «salir fuera de sí» ha creado todas las formas de los orgiástico: embriaguez, misticismo, enamoramiento, etcétera" (Ortega, 1981, p. 24).

Se aclara que este pseudoamor no tiene nada que ver con la noción esencial del amor o, mejor dicho, no se trata del amor verdadero en absoluto, tal como lo piensa el filósofo español. Siguiendo a Balakrishnan (2018) este enamoramiento sería "un estado de alma complejísimo donde el amor en sentido estricto tiene un papel secundario" (p. 411). Parece evidente la influencia de Platón en esta idea de amor como misticismo o locura temporal, en especial si consideramos el relato del rapto de Eros del alma del enamorado en el "Banquete". Me refiero a Platón, a propósito de esta noción de un Eros acechante, que encaja muy bien con el falso amor:

Pero, por otra parte, de acuerdo con la naturaleza de su padre, está al acecho de lo bello y de lo bueno; es valiente, audaz y activo, hábil cazador, siempre urdiendo alguna trama, ávido de sabiduría y rico en recursos, un amante del conocimiento a lo largo de toda su vida, un formidable mago, hechicero y sofista (Platón, p. 203).

De cualquier forma, Ortega nunca se dejó seducir por la influencia platónica, particularmente si se tiene en cuenta la dirección de este sentimiento y no tanto, como suele suponerse, el concepto de perfección. Atendiendo a la idea de enamoramiento de la teoría de la cristalización de Stendhal, que luego veremos, Carchidi dirá que el enamoramiento en el francés "se nos presenta como una hiperactividad del alma, más bien, un resultado estrecho y una parálisis relativa de nuestra vida consciente” (2002. p, 76).

\section{Amor como entrega}

Pues bien, al encantamiento le sigue un segundo momento, el de la entrega. En esta, dice el filósofo que nos sentimos absorbidos por el ser amado hasta la raíz de nosotros mismos, "como si nos hubiera arrancado de nuestro propio fondo vital y viviésemos trasplantados a él, con nuestras raíces vitales en él” (Ortega, 1981, p. 67). Literalmente somos succionados por el objeto amado "Merced a esto vive el enamorado, no desde sí mismo, sino desde el otro, como el hijo, antes de nacer, vive corporalmente de la madre, en cuyas entrañas está plantado y sumido (Ortega, 1981, p. 67). A decir de Ortega, lo que hay es un virtual salir-de-sí-mismo, así afirma en "Cuando el otro corresponde, sobreviene un período de «unión» transfusiva, en que cada cual 
traslada al otro las raíces de su ser y vive -piensa, desea, actúa-, no desde sí mismo, sino desde el otro" (Ortega, 1981, p. 23).

Este, por así decirlo, intercambio de sí-mismos, parece análogo a lo que Klocker llama primer registro del sentimiento amoroso en la fenomenología de Heidegger. En efecto, en el filósofo de la Selva Negra este amor como modo de la afectividad implica obligadamente una apertura, una tal que posibilite así mismo un "encontrarse" del Dasein en el modo afectivo del amor:

De esta manera, el amor pone al sí mismo ante lo insólito e imprevisible del hecho de que (inescrutable en su porqué) el otro simplemente "es" en lugar de "no ser" y de que es "quien es", y hace que el sí mismo experimente y acoja este factum como un "don” gratuito y único, digno de ser preservado y acompañado en su despliegue: "Tu propio ser [es] un regalo de Dios" (id. 28), dirá Heidegger el $1^{\circ}$ de mayo de 1925, y unos días después (el 13 de mayo) agregará: "Te hiciste para mí presencia [Gegenwart], cuando en ella te convertiste en un último regalo [Geschenk] para mí” (id. 31) (Klocker, 2016, p. 224).

Se trata, propiamente, del comprender emotivo. Como se recoge de la correspondencia entre Martin Heidegger y Hanna Arendt, y ante la pregunta por la "posibilidad" o campo de posibilidades que este temple anímico le abre y asigna a la propia existencia, se responderá: "Únicamente [la de] abrirnos [aufzuschließen] y dejar ser [sein lassen] lo que es" (Heidegger y Arendt citados en Klocker, 2016, p. 225). En su afán de desmitificación del fenómeno amoroso, escribirá Ortega en Para una psicología del hombre interesante:

[...] mi interpretación del fenómeno amoroso va en sentido opuesto a la falsa mitología que hace de él una fuerza elemental y primitiva que se engendra en los senos oscuros de la animalidad humana y se apodera brutalmente de la persona, sin dejar intervención apreciable a las porciones superiores y más delicadas del alma (Ortega, 1981, p. 69).

Parejamente, el filósofo vitalista dirá que podemos llegar a amar cosas muy distintas a un hombre o una mujer. Podrá tratarse, indistintamente, de un hijo, del arte, de la ciencia, de la patria... de Dios (Ortega, 1981, p. 5). En sentido estricto, daría lo mismo la cualidad del objeto con tal de que el amor se manifieste como "ese cálido y afirmativo interés nuestro en otro ser por él mismo” (Ortega, 1981, p. 15), pues no hay que olvidar que amor es esencialmente realización.

Ciertamente, este entregarse el enamorado a su amado puede ser visto como la clave del amor orteguiano. Somos capturados por el influjo del otro, por su personalidad (su alma, cuerpo, psique) que nos ha atrapado en el fondo de nuestro ser, a tal punto ( $\mathrm{y}$ de seguro es algo que todos hemos experimentado en algún momento) que no podemos sacarnos su imagen de nuestra cabeza; nos sentimos raros, vacíos, incompletos si no pensamos en él (o ella). En suma, estamos entregados a su amor. Aunque, cree Ortega, un alma reflexiva pudiera llegar a anticiparse a las consecuencias de esta misma entrega, tomando finalmente nuevas decisiones o, como veremos enseguida, nuevas elecciones. Escribe el filósofo "cabe que la voluntad del enamorado logre impedir su propia entrega a quien ama en virtud de consideraciones reflexivas -decoro social, moral, dificultades de cualquier orden. Lo esencial es que se sienta entregado al otro, cualquiera que sea la decisión de su voluntad" (Ortega, 1981, p. 67). Y luego añade "En el amor, lo típico es que se nos escapa el alma de nuestra mano y queda como sorbida por la otro (...) Merced a esto vive el enamorado, no desde sí mismo, sino desde el otro..." (Ortega, 1981, p. 67).

A decir verdad, lo que se transforma, dicho en los términos de ¿Qué es filosofía?, es el Yo como intimidad. Quedamos como desalmados, succionados por el ser-ante-mí del otro, tal y como ocurre en el amor «fundamental» de Heidegger "En la experiencia amorosa, en cambio, el sí-mismo se ve por un instante arrancado de este horizonte, y se vuelve capaz de 'no preguntar para qué [wozu] ni por qué [warum], sino solamente «ser»"” (Klocker, 2016, p. 229).

\section{AMOR COMO ELECCIÓN}

Asimismo, dirá el filósofo ibérico, el amor es elección, es "Una íntima adhesión a cierto tipo de vida humana que nos parece el mejor y que hallamos preformado, insinuado en otro ser” (Ortega, 1981, p. 32). Tal elección 
o preferencia ocurre cuando luego de la atracción inicial que naturalmente provoca el objeto amado, surge en nosotros lo decisivo en el amor: el interés. Según Ortega:

Tal sentimiento [el interés], cuando surge, liga el centro o eje de nuestra alma a aquella sensación externa; o, dicho de otro modo: no sólo somos atraídos en nuestra periferia, sino que vamos por nuestro pie hacia esa atracción, ponemos en ella nuestro ser todo (Ortega, 1981, p. 31).

De manera que, perfectamente se puede decir que tal interés es el amor. Se trata, en todo caso, de un interés muy peculiar, pues a diferencia del instinto tiende al exclusivismo, pues se centra solo en "ese alguien". Igualmente, este amor pareciera actuar al modo de un zum, en el sentido de que el objeto amado llena todo nuestro mundo: "Crisóstomo había muerto de amores por desdenes de Marcela" (Ortega, 1981, p. 45). Este rendimiento ontológico del amor se reiterará en varios pasajes de los Estudios sobre el amor. Por ejemplo, uno de los más conocidos es "[el amor] es un estar vitalmente con el otro" (Ortega, 1981, p. 11). Solo concediendo que Ortega "busca inaugurar una nueva ontología, nacida del descubrimiento de una realidad inédita y desconocida: la vida humana individual o lo que en términos más latos puede denominarse 'la existencia concreta"' (Cobián, 1958, p. 270), podemos comprender cómo es que el amor (su ética, su estética, su gnoseología) forma parte indisoluble de una vida que trasciende la inmanencia de un sujeto y que, por tanto, deja de ser intimidad (Cobián, 1958, p. 273).

Visto así, el amor formará parte esencial del proyecto ontológico que es la vida misma, donde el enamorado es la prueba palmaria de la conformidad consigo-mismo, y en tal medida no es sino una personalísima interpretación (dentro de las múltiples posibles) de nuestra particular circunstancia. Recordemos que, a juicio de San Martín, Ortega criticará al neokantismo por considerarlo justamente una filosofía que se aleja de la realidad. Frente a este alejamiento, dirá el filósofo madrileño, hay que "volver a las cosas mismas", tarea que, como podemos suponer, le corresponderá a la fenomenología.

Más todavía, si se lee con detalle el ensayo Amor en Stendhal, se entiende que el amor de Ortega consistirá en un darse súbitamente y para siempre, pues "un amor pleno, que haya nacido en la raíz de la persona, no puede verosímilmente morir" (1981, p. 11). Entonces, por medio del amor revelamos radicalmente nuestro fondo esencial. Así, Ortega describirá en nosotros una ratio essendi, que "actúa causalmente en la biografía de la persona, trayendo a ella, al más íntimo centro de ella, seres de determinado tipo y eliminando los restantes" (1981, p. 40). Fijémonos en la bellísima idea de las Meditaciones, "Lo amado es, por lo pronto, lo que nos parece imprescindible. ¡Imprescindible!" (Ortega, 1966, p. 312). Aquí hallamos una conexión directa con el problema del horizonte del proyecto del yo orteguiano -pudiéramos decir, con su determinación fenomenológica-, cuyo fundamento se encontraría en la metafísica ética del filósofo hispano, según la potente formulación de Bastida (2005). Quien ama, pareciera, solo es posible que ame desde dentro, radical y enteramente. Parafraseando a Hierro, se diría que el yo se transforma en pura ejecutividad amorosa (2005, p. 111).

Más allá de esto, se podría objetar una supuesta arbitrariedad de la voluntad en la elección del objeto (lo que llamaríamos el cálculo amoroso). Sin embargo, no perdamos de vista que en el pensador, el origen de tal decisión no está sino en el alma del enamorado, aunque debe reconocerse que, oportunamente, Ortega salva tal elección presentándola como un predicado ontológico no menos que psicológico. El mismo Ortega lo aclara:

Esta idea de que en el amor hay elección -una elección mucho más efectiva que cuantas se pueden hacer consciente, deliberadamente- y que esa elección no es libre, sino que depende de cuál sea el carácter radical del sujeto, tiene que parecer, desde luego, inaceptable a quienes conservan una interpretación psicológica del hombre que, a mi juicio, ha periclitado y debe sustituirse (Ortega, 1981, p. 37).

Lo que hay es una actividad sentimental específica, un entregarse sin querer, lo que no significa, sino que tal entrega ocurre en profundidades de la persona mucho más radicales que el plano de su voluntad. Dicho en clave ontológica: en su ser entero. De aquí que el erotismo de Ortega sea, a la postre, una metafísica del amor, o, 
si seguimos la conjetura que da pie a este trabajo, una expresión consolidada de su proyecto fenomenológico, de aquello que Ortega denominó desde su periodo de contacto con Husserl como filosofía primera. Ahora, no deja de ser complejo pensar dónde están esas profundidades que sobrepasan la voluntad personal. En otros términos, ¿Elegimos libremente a nuestro amado? Como no busco aquí discutir el concepto de libertad en el filósofo, solo sugeriré que la respuesta probablemente se halle en el propio yo de Ortega, en el sentido de que estamos irremisiblemente "obligados" a ser libres. De acuerdo con Secchi "Tenemos que hacer siempre algo, pero no sabemos qué. Entonces, la circunstancia nos presenta posibilidades ante las cuales tenemos que elegir. Estamos forzados a elegir y por lo tanto estamos condenados a ser libres" (2007, p. 27). Se trata, pues, del yo insondable del filósofo de la circunstancia.

De forma similar a como ocurre en Ortega, el fenómeno amoroso en Heidegger muestra una voluntad constreñida a la determinación del ser. Puede decirse así, la afectividad amorosa no es sino una determinación ontológica que pone en claro la libre presentación del otro. Dice Heidegger "El "espíritu [del amor] es la voluntad de que lo amado se encuentre en su propia esencia y allí permanezca" (Heidegger citado en Klocker, 2016, p. 226). Insistamos en que esta elección amorosa es una determinación no solo posible, sino, en los mismos dichos de Ortega, "una elección mucho más efectiva que cuantas se pueden hacer consciente, deliberadamente" (Ortega, 1981, p. 37). Desde luego el amor es un momento extraño -excepcional, me atrevería a decir- en nuestra conducta habitual. No es que andemos enamorándonos a la vuelta de la esquina ni a cada rato, sino que, tal como afirma Balakrishnan "Este «divino suceso» se produce únicamente cuando se dan unas condiciones específicas y muy rigurosas entre el sujeto y el objeto” (2018, p. 417).

Hay en Ortega una problemática aparición de la idea de decisión como Faktum de nuestro comparecer vital. Al igual que como en la fenomenología de la facticidad de Heidegger, en Ortega estamos arrojados a la existencia, lanzados al acontecimiento por antonomasia, "Pero eso que nos es dado, la vida, es un problema que necesitamos resolver nosotros" (Ortega, 1986, p. 35). Al punto que el amor bien podría considerarse el meollo de la vida orteguiana, el centro neurálgico de su efectividad. Secchi (2007) dirá la posibilidad de que el hombre se convierta en novelista de sí mismo. Es a lo que Medina llama generosidad romántica:

Ortega no reclama la vida -aunque lo reconozca y lo pida- porque ésta se encuentre subyugada, relegada a segundo término y haya que rehabilitarla en virtud de esa especie de generosidad romántica que ocupa el espíritu vitalista al que, no obstante, nuestro autor se encuentra de alguna manera vinculado, sino porque en su estudio ha de partir de lo real en cuanto necesario y ello se presenta en forma de un yo, enfrentado a su circunstancia en una relación necesaria para ambos términos. Ortega formula este hecho "frappant" más que ningún otro y lo sitúa en la base de su metafísica $(2015$, p. 60).

\section{AMOR CORTÉS}

En los Estudios sobre el amor se hace también una breve referencia al amor cortés (cuyo origen estaría en las Cortes de amor del siglo XII) como prototipo del amor puro. Sería, pues, "una forma extrema de erotismo espiritualista" (Ortega, 1981, p. 75), una suerte de modelo del romanticismo erótico. En él es esencial la distancia, al tratarse de un amor de nostalgia. De ahí que su imagen ideal sea el amor de Dante por Beatriz, puesto que al poeta le basta la sonrisa deseada de su amada para enamorarse. El Dante solo vive «per la speranza dell'ammirabile salute», prisionero de Beatriz, esperando -dice Ortega- su sonrisa gótica. A su vez, Beatriz desea solo el gesto, la carne en cuanto expresa alma.

El amor cortés será un amor de ideas, de la no consumación, bastante más cercano -curiosamente- a la noción de erotismo que presenta Roland Barthes en sus Fragmentos de un discurso amoroso, un amor que simula escenas posibles en las que el enamorado parece recrear una sofisticada -y en ocasiones, irrisoria- psicología del amor. En el amor cortés, reconoce Ortega, "triunfa en Dante el goticismo, con su alma de flecha ultrarreal, con su embriaguez de lo abstruso y su afán de fuga” (Ortega, 1981, p. 63). Si se mira bien, esta imagen de una Beatriz amanerada y prerrafaelista simboliza el poder del amor gentil en la cultura de la cortesía; más que eso, informa de una renovación, un renacimiento erótico en toda la cultura moderna. Plantea Holzapfel "Dante 
y la nueva forma de amar que introduce el amor cortés significan una ascensión de la mujer que ahora es vista como norma (para el hombre)" (1998, p. 54).

Además, Ortega se referirá al amor cortés como una mera forma del amor, como una cabal irrealización, un simple fingimiento de la Corte. Esto puede explicarse justamente por el momento histórico en que esta creación del espíritu surge: en la etapa más negra de la Edad Media, una coyuntura espiritual en la que solo el matrimonio es el lugar del amor real, de una cierta consumación terrenal. El amor cortés entonces es una transgresión (simbólica, pero transgresión, al fin y al cabo), no solo a la forma oficial del amor medioeval, sino a esa sensualidad que ponía a la carne como requisito indispensable de cualquier erotismo. Una expresión esencialmente sacroprofana. En cualquier caso, es palmario el sincretismo que el amor cortés representa, entre Edad Media y Renacimiento, entre sensualidad y evocación, matrimonio y pecaminosidad, en fin, entre Corte y religiosidad. Como sea, el centro sigue siendo la mujer. Sostiene Gerli:

En el centro de esta nueva filosofía del amor queda la mujer. Ella integra todos los ideales del amante y reparte el don de la salvación. Como la deidad cristiana en la especulación teológica, la dama es una abstracción moral: el foco de veneración, contemplación y meditación de todo cortesano que aspire a bien amar (1980, p. 317).

Siguiendo el razonamiento de Ivanovici (2011), esta breve alusión de Ortega al amor cortés, a pesar de no explicitar, por así decir, su sentido histórico, parece inscribirse del todo en la idea de cristianismo cósmico que Mircea Eliade expone en Lo sagrado y lo profano (1957). En palabras de Ivanovici:

Gestado lentamente en el seno de las humildes culturas folclóricas de los Balcanes, este cristianismo «cósmico» o mágico ofrece, en mi opinión, una clave pertinente hasta para la interpretación de un fenómeno cultural aristocrático, el famoso «amor cortés» nacido en Occitania (Paterson 1993), cantado por los trovadores (Riquer 1983; Nelli 1974; de Rougemont 2000), «codificado» por Andrés el Capellán (De Amore) y «romanceado» un poco más tarde, por un lado en el primer Roman de la Rose (Rose/Lauris) y por otro, en las historias caballerescas de «materia de Bretaña», estrenadas por Chrétien de Troyes (Lancelot/Chrétien) (2011, p. 389).

Es evidente que este amor de nostalgia, que refiere al amor cortés en Ortega, está bastante lejos de la idea de amor como fenómeno consustancial a la ejecutividad del Yo. Todo indica que Ortega ve en este amor de Corte tan solo un momento místico de lo amoroso. Podemos entonces decir del Dante que "A pesar de la aflicción que le ocasiona, el amador acepta su aegritudo amoris, pues ésta, como se ha dicho, es una prueba más de su amor incondicional y de su cortesía infinita” (Rodríguez, 2011, p. 135).

\section{AMOR COMO PERFECCIÓN}

En Amor en Stendhal, Ortega nos muestra la diferencia esencial entre su teoría del amor y la del escritor francés. Mientras que para el filósofo español nos enamoramos de algo o alguien "si es o parece ser perfección" (Ortega, 1981, p. 12), Stendhal sugerirá en su teoría de la cristalización que proyectamos elementos imaginarios sobre el objeto que creemos amar. En esta teoría, ficción, cristalización y error parecen ser una sola, ya que en Stendhal, piensa Ortega, "se ama el amor, y lo amado no es, en rigor, sino un pretexto" (Ortega, 1981, p. 8). Para el filósofo, lo que postula Stendhal no es otra cosa que una teoría del desamor, una explicación del fracaso del amor, todo lo contrario, a lo que la perfección amorosa supone o debiera suponer.

$\mathrm{Al}$ ver con detalle, es bastante obvio el tono platónico de esta idea orteguiana de perfección. En las Meditaciones se lee "Hay dentro de toda cosa la indicación de una posible plenitud. Un alma abierta y noble sentirá la ambición de perfeccionarla, de auxiliarla, para que logre esa plenitud. Esto es amor -el amor a la perfección de lo amado” (Ortega, 1966, p. 311). Lo dicho lleva a Ruiz a observar que para Ortega perfeccionar las cosas es amarlas, cuyo significado es "regalarles un sentido, que no es más ni menos que el suyo, pues el amor, envolviéndolas en una atmósfera favorable y benévola, despierta sus perfecciones" (2009, p. 131).

Ahora, no descuidemos lo que Ortega realmente entiende por perfección. No es que busquemos la perfección en las cosas, ni menos que elijamos lo perfecto dentro de una cierta gama o totalidad. Al contrario, 
nuestro amor justamente quiere potenciar lo que amamos por la simple razón de que creemos que lo amado es, en efecto, amable por si mismo. Vale decir que mediante el amor hacemos perfecto lo amado. Por último, esta elección está determinada por una única dirección del trayecto amoroso: el amor, dirá Ortega, brota de mí hacia el amado en dirección centrífuga. Como se ve, la analogía con la descarga masculina y femenina en el orgasmo parece bastante ajustada: el amor es virtualmente un emigrar hacia el objeto, "una fluencia, un chorro de materia anímica, un fluido que mana con continuidad como de una fuente [...], una irradiación psíquica que del amante va a lo amado" (Ortega, 1981, p. 5). En su famosa frase "el amor fluye en una cálida corroboración de lo amado" (Ortega, 1981, p. 6).

No quiero dejar pasar un aparente detalle sobre lo que se puede llamar una cierta antropología del amor. Es el problema de la zona de la personalidad (en nomenclatura de Ortega: del Yo) donde nace el amor. Siguiendo el análisis de Álvarez (2010) -que a su vez comenta el texto de Ortega Vitalidad, alma, espiritu (1924)-, se puede concluir que el amor yace, vive, se forja en nuestro espíritu, y no en nuestra alma, aunque el propio filósofo llegue a decir que "el alma de un enamorado huele a cuarto cerrado de enfermo" (1981, p.18). Aquí un pasaje de la interpretación de Álvarez:

[...] pensar o querer son actos míos, pero -ahora sí- en el sentido de que nacen de mi yo [...]. El espíritu [a diferencia del alma], en cambio, nos arranca de nuestra individualidad separada permitiendo -nos dice- la unión con los demás, de tal manera que lo que nos desindividualiza no es necesariamente aquello que nos deshumaniza, pues esa comunicación con los otros nos constituye precisamente como hombres (Álvarez, 2010, p. 44).

Por eso para Ortega el amor sexual es un componente decisivo de la perfección, a tal punto -y aquí parece haber una consideración antropológica del mayor calado- que tal forma de amor está destinada no a la conservación de nuestra especie, sino a su perfeccionamiento. Es indudable que el planteamiento de Ortega en esta fase de perfección del amor es de naturaleza palmariamente metafísica. En nuestra recepción, propiamente fenomenológica "Apenas comienza éste, experimenta el amante una extraña urgencia de disolver su individualidad en la del otro, y, viceversa, absorber en la suya la del ser amado" (Ortega, 1981, p. 12). El amor perfecto comparece, entonces, como un amor cosmológico, no psicológico: appetito di bellezza.

\section{CONCLUSIÓN}

El filósofo no presenta, ni mucho menos, una filosofía sistemática del amor. Lo que ensaya, a mi modo de ver, es una suerte de despsicologización del amor (ejemplificada en su crítica a la teoría de la cristalización de Stendhal) a partir de una fenomenología encajada en su tardía filosofía vitalista. De esta manera, esto queda en evidencia si se reconoce no solo las concomitancias fenomenológicas que pueden hallarse en los trabajos de Ortega y del primer Heidegger, sino también fundamentalmente a partir de las influencias tempranas de Husserl en la filosofia de la circunstancia de Ortega:

Esta correlación es lo que Husserl ha manifestado en el XX 27 de Ideen I con la estructura Ich und meine Umwelt (yo y mi mundo circundante), fundamento evidente de la fórmula «yo soy yo y mi circunstancia» (MQ, I, p.322), en la que Ortega desarrolla su concepto transitivo de la vida (Gutiérrez, 1998, p. 107-108).

Desde el momento del falso enamoramiento hasta la fase de perfección, el enamorado se relaciona de manera distinta con el objeto amado. Lo que hay, en definitiva, es el comparecer originario del otro. Por eso Ortega expresa en ¿Qué es filosofía?: "Yo soy quien ahora lo veo, él es lo que ahora yo veo -sin él y otras cosas como él, mi ver no existiría, es decir, no existiría yo” (Ortega, 1957, p. 89). El amor verdadero está referido a su propia perfección, a ese momento en que dejamos de estar "enloquecidos", obsesionados por el otro y, al mismo tiempo, hemos incluido en nuestra vida -en el sentido de una decisión voluntaria- todo aquello que tenga que ver, además, con la atracción sexual. El amor perfecto, visto así, deja de ser un estado patológico para convertirse en una disposición voluntaria y radicalmente sentida, independiente de si, a la larga, es o no correspondido, y si lo fuera, continúe un cierto tiempo, termine abruptamente o lo que sea. 
El amor de Ortega está lejos de la idea clásica del amor como pulsión a engendrar en lo bello. Incluso, si se adopta una interpretación, por así decir, más cosmológica de la teoría de Platón, se caería en cuenta de que la perfección del amado no determina en realidad la existencia de este amor. Pues, como bien señala Balakrishnan "si lo que amamos es la cualidad en el otro ser, ¿cómo explicar que el amor concluya si el objeto amado permanece idéntico?" (2018, p.416). Si el sentimiento amoroso es un sentimiento estético, es decir, un sentimiento donde se articulan la razón y la vida, con todo sentido puede considerarse al amor "un verdadero radical de una filosofía de la razón vital, que se mueve en el ámbito de la sensibilidad y de la imaginación, y que se orienta en la dirección de la síntesis entre lo racional y lo vital" (Gutiérrez, 2001, p. 140).

Se asiste, a fin de cuentas, a una meditación sincrética sobre el amor, a un realismo fenomenológico de lo amoroso que responde in toto a un pensamiento que intenta amalgamar -siguiendo el feliz comentario de Haro (2018) - pathos trascendental y pathos materialista. Para decirlo en la forma de una confrontación definitiva con Husserl, la fenomenología de Ortega requirió hacer del logos idealista un logos de la ejecutividad, un logos propio de su programa vital. Con Gutiérrez, un logos de vuelta a la vida. Brillantemente, Cobián (1958) llega a reconocer la nihilidad ontológica como nota esencial del hombre orteguiano. Si esto es así, todo sugiere que la filosofía del amor de Ortega revelaría al héroe romántico como el único modo de ser que pudiera enfrentar tal nihilismo bajo la forma de una axiología que, aislada del ser, permanezca supeditada a la vida.

¿Y qué es el amor, sino -como lee certeramente Holzapfel (1988)- estar arrancado de sí?

\section{REFERENCIAS}

Álvarez, E. (2010). La vida del yo: el problema del sujeto en Ortega. Signos Filosóficos, 12(24), 25-47. Recuperado de http://ref.scielo.org/fdkbct

Balakrishnan, M. (2018). Ortega y el amor. Éndoxa: series filosóficas. (42), 409-426. doi: https://doi.org/10.5944/en doxa.42.2018.23032

Bastida, A. (2005). Salvación y elegancia de la vida. La Metafísica ética de José Ortega y Gasset. En F. Llano y A. Castro (Eds.), Meditaciones sobre Ortega y Gasset (pp. 55-108). Madrid: Editorial Tébar.

Carchidi, L. (2002). "Estudios sobre el amor”. Radici letterarie e filosofiche del tema dell'amore in José Ortega y Gasset. [Estudios sobre el amor. Raíces literarias y filosóficas del tema del amor en José Ortega y Gasset]. En A. Lippolis (Ed.), Attidel XX Convegno [Associazione Ispanisti Italiani] (pp. 71-80). Recuperado de https://dialnet.unirioj a.es/servlet/libro?codigo $=271506$

Cobián, A. (1958). La ontología de Ortega y Gasset. Boletín del Instituto Riva-Agüero PUCP, (4), 261-342.

Gerli, E. (1980). "Eros y ágape”. El sincretismo del amor cortés en la literatura de la baja Edad Media castellana. En E. Rugg y A. Gordon, Actas del Sexto Congreso Internacional de Hispanistas (pp. 316-319). España: Universidad de Toronto.

Gutiérrez, A. (1998). Epokhé fenomenológica y raciovitalismo. Contrastes, 3, 105-122. doi: http://dx.doi.org/10.243 10/Contrastescontrastes.v3i0.1567

Gutiérrez, A. (2001). La filosofía de la razón vital como filosofía estética. Revista de Filosofía, (25), 139-160.

Haro, A. (2018). La teoría del amor en el pensamiento de Ortega a la altura de 1914. Claves ético-filosóficas y antropológicas de "Meditaciones del Quijote. Anales del Seminario de Historia de la Filosofia, 35(1), 175-204. doi: https://doi.org/10.5209/ASHF.59196

Heidegger, M. (2002). Ser y Tiempo. Santiago: Universitaria.

Hierro, J. (2005). La idea del yo en Ortega y Gasset. En F. Llano y A. Castro (Eds.), Meditaciones sobre Ortega y Gasset (pp.109-126). Madrid: Editorial Tébar.

Holzapfel, C. (1998). Lecturas del amor. Santiago: Universitaria.

Holzapfel, C. (2004). Seminario Aproximaciones filosóficas al erotismo [Material de aula]. Doctorado en Filosofía mención estética y teoría del arte. Universidad de Chile, Santiago. 
Ivanovici, V. (2011). Secularizando el amor cortés. En C. Strosetzki, Actas selectas del VII Congreso Internacional de la Asociación de Cervantistas (pp. 389-410). España: Centro de Estudios Cervantinos.

Klocker, D. (2016). La significación del fenómeno amoroso en el pensamiento de Martin Heidegger. Ideas y valores, 65(161), 217-245. doi: https://doi.org/10.15446/ideasyvalores.v65n 161.42402

León, E. (2009). El giro hermenéutico de la fenomenológica en Martín Heidegger. Polis (22), 1-14. Recuperado de h ttp://journals.openedition.org/polis/2690

López, F. (2000). La interpretación Orteguiana de la fenomenología: el yo como lo ejecutivo. Convivium, (13), 91-108. Recuperado de https://www.raco.cat/index.php/Convivium/article/view/73184

Medina, R. (2015). Ensayo sobre la idea de poder en el pensamiento de José Ortega y Gasset (Tesis doctoral). Universidad Complutense de Madrid: Madrid. Recuperado de https://eprints.ucm.es/54315/1/5327075369.pdf

Ortega, J. (1957). ¿Qué es fllosofía? Madrid: Revista de Occidente.

Ortega, J. (1966). Meditaciones del Quijote, en Obras completas. Madrid: Revista de Occidente.

Ortega, J, (1981). Estudios sobre el amor. Antología. Buenos Aires: Revista de Occidente en Alianza Editorial.

Ortega, J. (1986). Unas Lecciones de Metafísica. Madrid: Revista de Occidente en Alianza Editorial.

Platón. (2000). Diálogos III. Fedón, Banquete, Fedro. Madrid: Gredos.

Rodríguez, R. (2011). La concepción amatoria medieval en la Epistola de Francisco de Terrazas (S. XVI). Revista de Humanidades, (24), 115-139. Recuperado de https://www.redalyc.org/articulo.oa?id=3212/321227219006

Ruiz, J. (2009). La idea de filosofia en Ortega y Gasset (Tesis doctoral). Universidad Complutense de Madrid. Madrid. Recuperado de https://eprints.ucm.es/9522/1/T31067.pdf

Ruiz, J. (2011). Séneca en Ortega. Contrastes. Revista Internacional de Filosofia, 16, 347-364. doi: http://dx.doi.org/ 10.24310/Contrastescontrastes.v16i0.1584

San Martín, J. (2012). La fenomenología de Ortega y Gasset. Madrid: Biblioteca Nueva.

Secchi, G. (2007). La vida humana en el pensamiento de Ortega y Gasset. El hombre como novelista de sí mismo (Tesis de Magíster). Universidad de Chile.

Tuttle, H. (1981). Ortega's vitalism in relation to aspects of Lebensphilosophie and phenomenology. [El vitalismo de Ortega en relación con los aspectos de la Lebensphilosophie y la fenomenología]. Southwest Philosophical Studies, 6, 88-92. Recuperado de https://collections.lib.utah.edu/ark:/87278/s6xw5357

\section{BY-NC-ND}

